\title{
Atividades práticas e o ensino-aprendizagem de ciência(s): mitos, tendências e distorções
}

\section{Practical activities and the teaching and learning of science(s): myths, trends and distortions}

Fernanda Bassoli ${ }^{1}$

Resumo: Quando se fala em deficiências na educação científica, logo se remete à ausência de aulas experimentais na Educação Básica, de modo que as atividades práticas investigativas são vistas, na atualidade, como sinônimo de inovação no ensino. Nesse artigo, de cunho teórico, dialoga-se com os referenciais teóricos da educação em ciência, e discutem-se as tendências, mitos e concepções sobre a natureza da ciência presentes nas diversas modalidades de atividades práticas, assim como os tipos de interatividade que tais atividades propiciam. Nesse sentido, a autora parte de suas vivências como professora e pesquisadora da Educação Básica e como formadora de professores de ciências naturais.

Palavras-chave: Ensino de ciências. Atividades práticas investigativas. Natureza da ciência.

\begin{abstract}
When it comes examining the deficiencies in science education, one soon focuses to the absence of experimental classes, so that inquiry activities are seen today as a synonym for innovation in education. In this theoretically oriented article, I dialogue with the theoretical references of science education, and discuss trends, myths and conceptions, present in the various forms of practical activities, and of the nature of science, as well as the types of interactivity that these activities provide. In this article I start from my experiences as a teacher and researcher of basic education and as a trainer of teachers of natural sciences.
\end{abstract}

Keywords: Science education. Inquiry activities. Nature of science.

\footnotetext{
${ }^{1}$ Colégio de Aplicação João XXIII, Universidade Federal de Juiz de Fora (UFJF), Rua Visconde de Mauá, 300, Santa Helena, CEP 36015-260, Juiz de Fora, MG, Brasil. E-mail: <fernanda.bassoli@ufff.edu.br>
} 


\section{Introdução}

Podemos constatar, entre professores e pesquisadores, uma unanimidade acerca da importância da realização de atividades práticas no processo de ensino-aprendizagem das ciências naturais. Esse aparente consenso deriva, sobretudo, de uma concepção empírica sobre a ciência e seus métodos, atribuindo a esta um caráter eminentemente prático. Entretanto, há, na prática docente, um abismo entre a importância atribuída às atividades práticas e a sua execução, o que tem sido relatado por diversos trabalhos (ANDRADE; MASSABNI, 2011; COQUIDÉ, 2008; MUNFORD; LIMA, 2007).

Durante o período em que atuei como supervisora de estágios em docência em Ciências e Biologia, deparei-me com essa realidade, a cada semestre letivo, por meio das narrativas de meus alunos - dispersos pelas redes de ensino estadual, municipal e particular - sobre a quase inexistência de aulas práticas nas turmas acompanhadas. De modo que, quando presentes, as atividades práticas objetivavam a demonstração de conteúdos teóricos e comprovação de teorias. Tal situação também foi descrita na pesquisa de Andrade e Massabni (2011), e explicita uma visão "deformada" sobre a ciência, conforme discutirei neste ensaio. Segundo estes autores:

Os professores, ao deixarem de realizar atividades práticas podem estar incorporando formas de ação presentes historicamente no ensino, pautado por uma abordagem tradicional, sem maiores reflexões sobre a importância da prática na aprendizagem de ciências. (ANDRADE; MASSABNI, 2011, p. 836)

Acrescento que, mesmo os que reconhecem a importância das atividades práticas e trabalham em contextos que favorecem a realização destas atividades, podem apresentar dificuldades para realizá-las, tendo em vista sua pouca familiarização com as práticas durante o processo de escolarização, além de outros fatores que serão mencionados neste trabalho.

Cabe, inicialmente, problematizar o que se entende por atividades práticas, tendo em vista a pluralidade de concepções existentes sobre esse termo. Nesse sentido, compartilho a definição apresentada por Andrade e Massabni (2011), de base piagetiana, que compreende as atividades práticas como:

\section{[...] Aquelas tarefas educativas que requerem do estudante a experiência direta com o material presente fisicamente, com o fenômeno e/ou com dados brutos obtidos do mundo natural ou social. Nesta experiência, a ação do aluno deve ocorrer - por meio da experiência física -, seja desenvolvendo a tarefa manualmente, seja observando o professor em uma demonstração, desde que, na tarefa, se apresente o objeto materialmente. (ANDRADE; MASSABNI , 2011, p. 840 , grifo nosso)}

A definição de atividade prática ora destacada tem, portanto, como ponto central, a presença material dos objetos, espécimes ou fenômenos a serem investigados, independentemente do tipo de contato que os estudantes estabelecem com eles. Há, entretanto, outras defi- 
nições na literatura, como as de Krasilchik (2008) - que não considera as demonstrações como atividades práticas por não envolverem, diretamente, os alunos na obtenção dos dados - e as de Barreto Filho (2001 apud ANDRADE; MASSABNI, 2011), que incluem até procedimentos de leitura e de escrita como atividades práticas, desde que objetivem a obtenção de informações por parte dos alunos.

Embora a definição de Andrade e Massabni (2011) tenha como base a materialidade dos objetos, podendo, portanto, prescindir do contato direto por parte dos alunos, é desejável que haja a maior interatividade possível destes com os objetos e fenômenos, tanto física (hands on), emocional (hearts on), mas, sobretudo, intelectual (minds on), o que tem sido bastante destacado no contexto da aprendizagem científica em espaços educativos não escolares (MARANDINO, 2008, p. 22).

Nesta perspectiva, cabe aos professores elaborarem estratégias metodológicas que favoreçam uma maior interatividade entre os objetos de estudo e os alunos, assim como entre aluno-aluno e aluno-professor, o que podemos chamar de interatividade social - social on - (PAVÃO; LEITÃO, 2007, p. 41), de modo a favorecer a construção de significados pelos educandos.

A partir de minha vivência como professora/pesquisadora da Educação Básica e como formadora de professores de ciências, discuto, nas próximas seções: as diversas "modalidades" de atividades práticas e os tipos de interatividade que propiciam; as concepções sobre a natureza da ciência subjacentes à atividade experimental em momentos históricos distintos, e alguns mitos que permeiam a realização das atividades práticas no cotidiano escolar, empreendendo um diálogo com os referenciais teóricos da educação em ciências.

\section{Concepções de aulas práticas e tipos de interatividade que propiciam}

Campos e Nigro (1999), numa tentativa de diferenciar as modalidades de atividades práticas, categorizam-nas em: (i) demonstrações práticas; (ii) experimentos ilustrativos; (iii) experimentos descritivos, e (iv) experimentos investigativos - os quais denominarei, neste artigo, de atividades práticas investigativas, ou, simplesmente, atividades investigativas. Descreverei, a seguir, estas modalidades de atividades práticas, analisando os tipos de interatividade que cada uma delas propicia. Para tal, utilizarei as categorias de interatividade descritas por Marandino (2008) e Pavão e Leitão (2007).

\section{Demonstrações práticas}

As demonstrações práticas são atividades realizadas pelo professor, às quais o aluno assiste sem poder intervir, possibilitando a este maior contato com fenômenos já conhecidos, mesmo que ele não tenha se dado conta deles. Possibilitam, também, o contato com coisas novas, como: equipamentos, instrumentos e fenômenos (CAMPOS; NIGRO, 1999). De acordo com Krasilchik (2008):

A utilização de demonstração é justificada em casos em que o professor deseja economizar tempo, ou não dispõe de material suficiente para a 
toda a classe, servindo também para garantir que todos vejam o mesmo fenômeno simultaneamente, como ponto de partida comum para uma discussão ou para uma aula expositiva. (KRASILCHIK, 2008, p. 85)

Nesse sentido, a interatividade entre os alunos e os fenômenos/objetos é muito reduzida, não havendo interatividade física direta (hands on). Entretanto, estas práticas podem proporcionar interatividade emocional (hearts on), sobretudo quando se trata de recursos atrativos, como, por exemplo, reações químicas do tipo "show de ciência". Vale ressaltar que nenhum dos tipos de interatividade garante a interatividade intelectual (minds on), embora esta possa ser favorecida pelas demais.

Deste modo, caberá ao professor problematizar as demonstrações práticas de modo a propiciar o engajamento intelectual dos alunos com os objetos e fenômenos apresentados. Da mesma forma, os alunos podem ser organizados em grupos para discutir determinadas questões que envolvam os objetos de estudo, favorecendo, assim, a interatividade social (social on).

\section{Experimentos ilustrativos}

São atividades que os alunos podem realizar por si mesmos e que cumprem as mesmas finalidades das demonstrações práticas, possibilitando um maior contato com fenômenos já conhecidos. Portanto, estas atividades envolvem, necessariamente, a interatividade física, propiciando, também, a interatividade social quando os alunos realizam os experimentos em grupos. Da mesma forma que os experimentos demonstrativos, a ocorrência da interatividade intelectual dependerá de estímulos do professor, como, por exemplo, por meio de problematizações, sendo, entretanto algo muito individual, dependendo da predisposição do aluno a se engajar intelectualmente com o objeto de estudo. A interatividade emocional é igualmente particular, de modo que, para alguns alunos, um determinado experimento pode ser extremamente emocionante, não tendo, para outros, nenhum significado emocional ou afetivo.

\section{Experimentos descritivos}

São atividades que o aluno realiza, não sendo, obrigatoriamente, dirigidas o tempo todo pelo professor, favorecendo, com isso, o contato direto do aluno com coisas ou fenômenos que precisa apurar, sejam ou não comuns no seu dia a dia (CAMPOS; NIGRO, 1999). Nesse sentido, a interatividade física e intelectual assume um lugar de destaque, promovendo, também, a interação social entre os alunos, quando realizada em grupos, e entre os alunos e o professor, já que este pode dar uma atenção mais individualizada aos grupos. Este tipo de atividade prática, por se basear no "descobrimento" de fenômenos por parte dos estudantes - que deverão tanto descrever os fenômenos observados, como chegar às suas próprias conclusões sobre eles -, aproxima-se das atividades investigativas descritas a seguir. No entanto, não implicam a realização de testes de hipóteses. 


\section{Experimentos investigativos}

Os experimentos investigativos, ou atividades práticas investigativas, são aqueles que exigem grande participação do aluno durante sua execução. Diferem das outras atividades por envolverem, obrigatoriamente, discussão de ideias, elaboração de hipóteses explicativas e experimentos para testá-las (CAMPOS; NIGRO, 1999). Nesse sentido, este tipo de atividade estimula, ao máximo, a interatividade intelectual, física e social, contribuindo, sobremaneira, para a formação de conceitos.

$\mathrm{Na}$ literatura, são encontradas diferentes denominações para o ensino por investigação (MUNFORD; LIMA, 2007; ZOMPERO; LABURU, 2011) como: inquiry, ensino por descoberta, aprendizagem por projetos, questionamentos, resolução de problemas, dentre outras.

Nos últimos anos, o ensino e a aprendizagem de atividades práticas investigativas vêm ganhando espaço e importância no Brasil (BEVILACQUA; COUTINHO-SILVA, 2007; GALIAZZI; GONÇALVES, 2004; GOMES; BORGES; JUSTI, 2008; MUNFORD; LIMA, 2007; RAMOS; ROSA, 2008; ZANON; FREITAS, 2007). Apesar de haver uma falta de consenso acerca das atividades investigativas, podemos assinalar, como ponto de convergência entre as diversas concepções, a presença da problematização - enquanto propulsora da investigação (ZOMPERO; LABURU, 2011) - e a perspectiva de aproximar a atividade dos cientistas ao ensino de ciências (TRÓPIA, 2011).

Segundo Zompero e Laburu (2011, p. 68): “A perspectiva do ensino com base na investigação possibilita o aprimoramento do raciocínio e das habilidades cognitivas dos alunos, e também a cooperação entre eles, além de possibilitar que compreendam a natureza do trabalho científico". Atualmente, a investigação é utilizada no ensino com outras finalidades que as presentes nas reformas da década de 1960 - cujo objetivo central era a formação de cientistas -, como o desenvolvimento de habilidades cognitivas nos alunos, a realização de procedimentos como: elaboração de hipóteses, anotação e análise de dados e o desenvolvimento da capacidade de argumentação (ZOMPERO; LABURU, 2011).

Para Munford e Lima (2007), esta perspectiva de ensino constitui uma forma de aproximação entre a "ciência dos cientistas", considerando-se o seu contexto cultural, e a "ciência escolar", de modo a trazer, para a escola, aspectos inerentes à prática dos cientistas, demarcando, entretanto, as diferenças entre estas duas "ciências". As autoras ressaltam algumas concepções que consideram equivocadas acerca do ensino por investigação: (i) o ensino por investigação envolve, necessariamente, atividades práticas ou experimentais; (ii) envolve atividades bastante "abertas", em que os estudantes têm autonomia para escolher questões, determinar procedimentos de investigação e de análise de dados; (iii) todos os conteúdos deveriam ser desenvolvidos por meio de uma abordagem investigativa.

A partir das colocações acima, é importante distinguir o "ensino por investigação" das "atividades práticas investigativas". O primeiro é uma perspectiva de ensino baseada na problematização, elaboração de hipóteses e teste de hipóteses, seja por meio da pesquisa, seja por meio da experimentação, podendo, portanto, envolver ou não atividades experimentais. As atividades práticas investigativas situam-se no contexto do ensino por investigação, compartilhando os mesmos objetivos. Entretanto, baseiam-se, imprescindivelmente, na experimentação.

De acordo com Munford e Lima (2007), está havendo uma ampliação significativa no entendimento dos professores sobre o que é ensino por investigação e sobre suas aproximações 
e diferenças em relação a um ensino experimental ou baseado em atividades de "investigação simples e ritualística", gerando a certeza "de que é preciso promover um ensino mais interativo, dialógico e baseado em atividades capazes de persuadir os alunos a admitirem as explicações científicas para além dos discursos autoritários, prescritivos e dogmáticos" (MUNFORD; LIMA, 2007, p. 78).

$\mathrm{Na}$ seção seguinte, faço uma rápida análise histórica das atividades práticas no ensino de ciências, destacando as diferentes concepções sobre a natureza da ciência que influenciaram a compreensão acerca das atividades investigativas. Para maiores detalhes sobre as transformações históricas do ensino de ciências no Brasil, sugiro os artigos de Krasilchik (2000) e Chassot (2004), e sobre os percursos históricos das atividades investigativas, sugiro a leitura dos trabalhos de Trópia (2009, 2011) e Zompero e Laburu (2011).

\section{Atividades práticas no ensino de ciência(s): de que ciência estamos falando?}

As maiores reformas educacionais da educação científica aconteceram nos últimos cinquenta anos. A primeira reforma curricular, ocorrida entre as décadas de 1950 e 1970, foi motivada pelo lançamento do satélite Sputnik pela antiga União Soviética, e patrocinada pela National Science Foundation (NSF), dos Estados Unidos, e pela Fundação Nuffield, do Reino Unido (DUSCHL, 2008). O objetivo do acordo de reforma curricular era produzir programas que levassem os estudantes a "pensarem como cientistas", estimulando-os a seguir carreiras científicas.

Segundo Trópia (2011), a investigação científica presente nestes programas apresentava uma concepção de ciência neutra, afastada da sociedade, em que o objetivo fundamental do ensino de ciências era a vivência do método científico, sob a égide de um modelo de desenvolvimento em que mais ciência e mais tecnologia gerariam mais riqueza e bem-estar social. "Assim, desenvolver nas crianças o interesse pela ciência e pela execução do método científico levaria a uma nova geração de cientistas que impulsionariam o desenvolvimento científico, econômico e social" (TRÓPIA, 2011, p. 133).

A ideia de ensino por investigação sofreu modificações em função das necessidades políticas, econômicas e sociais pelas quais a sociedade passou durante várias décadas, havendo, no entanto, uma maior ênfase na utilização de atividades investigativas pelos americanos (ZOMPERO; LABURU, 2011). Neste sentido, baseados em Deboer (2006), os autores citam três fases do ensino por investigação: (i) descoberta ou abordagem heurística, na qual os estudantes teriam de explorar o mundo natural; (ii) verificação, na qual os alunos teriam de confirmar fatos ou princípios científicos por meio da utilização do laboratório, e (iii) ensino por investigação.

No primeiro caso, a concepção de ciência que norteia a "descoberta" é a de uma ciência indutiva e empírica. Segundo Chalmers (1993), a ciência indutiva começa com procedimentos de observações detalhadas para construir generalizações.

Por isso, os estudantes tinham que aprender a observar o mundo natural e formular conclusões a partir de suas observações. Ainda de acordo com o referido autor, essa abordagem para o Ensino de Ciências, con- 
siderando a indução, foi uma justificativa para o surgimento de práticas que envolviam a utilização do laboratório. (ZOMPERO; LABURU, 2011, p. 70)

Esta perspectiva de ensino reflete uma visão "deformada" da ciência, desconsiderando o papel da teoria como norteadora da observação (CHALMERS, 1993), o que, também, é destacado por Cachapuz et al. (2005, p. 45), quando afirmam: “Toda investigação e mesmo a procura de dados, vem marcadas por paradigmas teóricos, ou seja, por visões coerentes, articuladas, que orientam a dita investigação".

No segundo caso, a verificação, a concepção de ciência que é evidenciada é a de uma ciência infalível, dogmática, baseada em verdades absolutas, as quais os alunos deverão "desvelar" por meio do "Método Científico". Segundo Cachapuz et al. (2005, p. 62):

A ideia de "método científico", em resumo, tem perdido hoje as suas maiúsculas, ou seja, a sua suposta natureza de caminho preciso - conjunto de operações ordenadas - e infalível, assim como sua suposta neutralidade. Isto não supõe, no entanto, negar o que de específico a ciência moderna tem dado ao tratamento dos problemas: a ruptura com um pensamento baseado em estudos pontuais, nas "evidências" do sentido comum e em certezas dogmáticas, introduzindo um raciocínio que se apoia num sistemático questionamento do óbvio e numa exigência de coerência global, que se tem mostrado de uma extraordinária fecundidade.

Já no último caso, "os alunos não teriam que descobrir algo, mas por meio da utilização de método científico, os estudantes teriam que procurar soluções para questões que eles não sabiam a resposta." (ZOMPERO; LABURU, 2011, p. 71). Esta perspectiva do ensino por investigação também se baseia em uma perspectiva distorcida da ciência, sobrevalorizando-se o "método científico", conforme destacado acima por Cachapuz et al. (2005).

Segundo estes autores, a grande presença destas visões deformadas sobre a ciência é o resultado da ausência de reflexão epistemológica e de aceitação acrítica de um ensino de transmissão de conhecimentos já elaborados. Neste sentido, as propostas de inclusão da dimensão que enfoca as relações entre Ciência, Tecnologia, Sociedade e Ambiente (CTSA), emergentes na década de 1970, têm buscado promover a contextualização da atividade científica.

Segundo Zompero e Laburu (2011), com os agravos causados ao meio ambiente, o ensino de ciências, a partir da década de 1970, passou novamente a ter a preocupação de propor uma educação que levasse em conta os aspectos sociais relativos ao desenvolvimento científico e tecnológico.

Nessa perspectiva, as atividades investigativas eram utilizadas como orientação para ajudar os estudantes a pesquisar problemas sociais como o aquecimento global, a poluição, dentre outros. Sendo assim, o objetivo da educação científica era o entendimento dos conteúdos, dos valores culturais, da tomada de decisões relativas ao cotidiano e à resolução de problemas. (ZOMPERO; LABURU, 2011, p. 72) 
Segundo Duchl (2008), a segunda reforma na educação científica nos Estados Unidos e no Reino Unido teve início na década de 1980, e persiste até hoje como parte de movimentos nacionais, denominados de "Ciência para Todos", nos Estados Unidos, e "Entendimento Público da Ciência", no Reino Unido. Estes movimentos têm em comum o objetivo de promover a alfabetização científica da população, a fim de que os cidadãos possam participar da agenda econômica e democrática em uma sociedade globalizada. Nesse sentido, o ensino por investigação, que leva os alunos a desenvolverem atividades investigativas, não tem mais, como na década de 1960, o objetivo de formar cientistas.

Algumas concepções atuais do ensino de ciências por investigação buscam compreender a natureza da investigação científica dentro de outros contextos que eram silenciados na concepção de ciência neutra a partir da aplicação do método científico nas propostas curriculares das décadas de 1950 e 1960 (TRÓPIA, 2009, p. 41).

No fim do século XX, as atividades práticas investigativas começaram a ser retomadas e a se difundirem, da América do Norte e Europa, para o Brasil, diferindo-se, segundo Trópia (2011, p. 122), "das perspectivas anteriores por influência das discussões sobre a natureza da Ciência e da apropriação de relações entre a Ciência e a sociedade no ensino de ciências".

Podemos, então, concluir que as possibilidades de aprendizagem proporcionadas pelas atividades práticas dependem de como estas são propostas e desenvolvidas com os alunos (ANDRADE; MASSABNI, 2011), podendo servir a uma ampla gama de concepções sobre ensino-aprendizagem e, também, sobre a ciência. Se um dos objetivos do ensino por investigação é "aproximar a ciência escolar da ciência dos cientistas" (MUNFORD; LIMA, 2007, p. 16), de modo a não só ensinar ciência, mas, também, ensinar "sobre ciência", deve-se ter uma atenção especial sobre a visão de ciência que é transmitida e/ou reforçada, quando se realizam as atividades experimentais com os estudantes.

Em pesquisa realizada por Trópia (2009), com o objetivo de investigar o aprendizado de Biologia em aulas práticas investigativas, o autor concluiu que, embora elas possibilitassem o aprendizado sobre os "processos da ciência", a visão de ciência que prevaleceu durante a realização de entrevistas com os alunos foi uma visão empirista/indutivista, em consonância com a visão apresentada por sua professora. Estes resultados vão ao encontro de diversos estudos que têm evidenciado as discrepâncias entre a imagem da ciência proporcionada pela epistemologia contemporânea e determinadas concepções docentes amplamente enraizadas, marcadas por um empirismo exacerbado (CACHAPUZ et al., 2005).

De acordo com os pesquisadores supracitados, as numerosas investigações recolhidas na literatura confirmam a extensão da imagem distorcida e empobrecida da ciência e da tecnologia, assim como a necessidade de transcendê-la, de modo a atrair o interesse dos estudantes e proporcionar sua imersão numa cultura científica. Estas pesquisas sinalizam, portanto, a importância de se problematizar aspectos epistemológicos da ciência no âmbito da formação de professores.

\section{Superando a visão deformada da ciência...}

Superar a visão deformada de ciência tão enraizada no ensino e nas concepções das pessoas - sejam elas estudantes, professores, trabalhadores das mais diversas áreas e, até mes- 
mo, pesquisadores -, implica se (re)pensar não só as atividades práticas na educação científica, mas, sobretudo, o currículo de ciências, de forma a favorecer a construção de conhecimentos científicos (da ciência e sobre a ciência).

Nesta direção, os parâmetros curriculares nacionais para o ensino de ciências no Brasil (BRASIL, 1998) - em consonância com as tendências que têm se estabelecido mundialmente - têm enfatizado a importância de se desenvolver não só os conhecimentos "conceituais" já referidos, mas, também, os conhecimentos "procedimentais" e "atitudinais".

Apresentarei no Quadro 1 diversos aspectos a serem pensados no âmbito do currículo de ciências segundo Cachapuz et al. (2005), de modo a favorecer a construção de conhecimentos científicos em sintonia com uma visão mais atualizada da natureza da ciência. Em seguida, voltando-me mais para o cotidiano escolar, discuto, brevemente, alguns mitos acerca das atividades práticas no ensino de ciências que contribuem ora para perpetuar a visão deformada sobre a ciência, ora para justificar a não-inclusão destas atividades no ensino.

\section{Desmitificando as atividades práticas no Ensino de Ciências}

Discutirei, a seguir, os três grandes mitos que se fazem presentes no cotidiano escolar acerca das atividades práticas.

Mito 1: O caminho para aprender ciência e seus métodos é o "aprender fazendo" ou o "descobrir aprendendo".

Esta crença baseia-se em uma visão amplamente difundida entre os professores de que o trabalho experimental ensina os estudantes sobre o que é a ciência e a sua metodologia (HODSON, 1990 apud PRAIA; CACHAPUZ; GIL-PÉREZ, 2002). Segundo este autor, o trabalho experimental, tal como é conduzido em muitas escolas, é de concepção pobre, confuso e não produtivo, de modo que os professores o utilizam sem uma adequada reflexão, mantendo o mito de que ele é a solução para os problemas de aprendizagem.

Por outro lado, quando o trabalho experimental não é realizado, ou é muito pouco utilizado, como acontece na realidade educacional brasileira, as deficiências na educação científica são atribuídas (entre outros "culpados”) à ausência de atividades de experimentação, vistas, sob essa ótica, como a "panaceia" do ensino de ciências.

De acordo com Hodson (1990 apud PRAIA; CACHAPUZ; GIL-PÉREZ, 2002, p. 258), "muito do que se faz está mal concebido e não apresenta qualquer valor educacional, urge redefinir e reorientar a noção que os professores têm sobre o trabalho prático". Com esta afirmativa, o autor se refere a uma concepção de atividade prática empirista/indutivista, já criticada neste artigo, em que:

Não se analisa e reflete nos resultados, à luz do quadro teórico e das hipóteses enunciadas, mas apenas se constata o que era mais do que previsível que acontecesse - a experiência realizou-se para dar determinado resultado já esperado e conhecido de antemão. [...] A experiência surge, quase sempre, como algo episódico, ligada a uma visão heroica do cientista; ignora, pois, os contextos sociais, tecnológicos e culturais 
Quadro 1. Aspectos a incluir no currículo de ciências para favorecer a construção de conhecimentos científicos

1. Apresentam-se situações problemáticas abertas (com o objetivo de que os alunos possam tomar decisões para precisá-las) de um nível de dificuldade adequado (correspondente a sua zona de desenvolvimento proximal);

2. Propõe-se uma reflexão sobre o possível interesse das situações propostas que dê sentido ao seu estudo (considerando a sua relação com o programa geral de trabalho adotado, as possíveis implicações CTSA...); Presta-se atenção, em geral, em potencializar atitudes positivas e que o trabalho se realize num clima próximo ao que é a investigação coletiva (situações em que as opiniões, interesses etc. de cada indivíduo contam), e não num clima de submetimento de tarefas impostas por um professor/"capataz".

Procura-se evitar toda discriminação (por razões étnicas e sociais...) e, em particular, o uso de uma linguagem sexista, transmissora de expectativas negativas para as mulheres;

3. Propõe-se uma análise qualitativa, significativa, que ajude a compreender e a balizar as situações propostas (à luz dos conhecimentos disponíveis, do interesse do problema etc.) e a formular perguntas operativas sobre o que se procura;

Mostra-se, por outra parte, o papel essencial da matemática como instrumento de investigação, que intervém desde a formulação de problemas até a análise dos resultados, sem cair em operativismos cegos;

4. Propõe-se a emissão de hipóteses, fundamentadas nos conhecimentos disponíveis, suscetíveis de orientar o tratamento das situações e de tornar explícitas, funcionalmente, as pré-concepções.

Presta-se atenção às pré-concepções (que, insistimos, devem ser contempladas como hipóteses).

Presta-se atenção à atualização dos conhecimentos que constituem pré-requisitos para o estudo empreendido;

5. Propõe-se a elaboração de estratégias (no plural), incluindo desenhos experimentais.

Presta-se atenção à atividade prática em si mesma (montagens, medidas...) dando à dimensão tecnológica o papel que lhe corresponde neste processo;

Incentiva-se, quando possível, a incorporação da tecnologia atual aos desenhos experimentais (eletrônica, informática etc.), com o objetivo de favorecer uma visão mais correta da atividade técnico-científica contemporânea.

6. Propõe-se a análise profunda dos resultados (sua interpretação física, confiabilidade etc.) à luz do corpo de conhecimentos disponíveis, das hipóteses consideradas e dos resultados das outras equipes.

Propõe-se uma reflexão sobre os possíveis conflitos entre alguns resultados e as concepções iniciais, favorecendo a "autorregulação" dos trabalhos dos alunos;

Propicia-se que os estudantes comparem a sua evolução conceitual e metodológica com a experimentada historicamente pela comunidade científica.

7. Propõe-se a consideração de possíveis perspectivas (redelineamento do estudo a outro nível de complexidade, problemas derivados...). Considerando-se, em particular, as implicações CTSA do estudo realizado (possíveis aplicações, repercussões negativas, tomadas de decisões...).

Pede-se a elaboração de "produtos" (protótipos, coleções de objetos, cartazes...) pondo em ênfase a estreita relação ciência-tecnologia;

8. Pede-se um esforço de integração que considere a contribuição do estudo realizado à construção de um corpo coerente de conhecimentos, as possíveis implicações em outros campos etc.

Pede-se algum trabalho de construção de sínteses, mapas conceituais etc., que ponha em relação conhecimentos diversos;

9. Presta-se atenção à comunicação como aspecto essencial da atividade científica.

Propõe-se a elaboração de memórias científicas do trabalho realizado. Pede-se a leitura e comentário crítico de textos científicos.

Presta-se atenção à verbalização, solicitando comentários significativos que evitem o operativismo mudo; 10. Potencializa-se a dimensão coletiva do trabalho científico organizando-se equipes de trabalho e facilitando a interação entre as equipes e a comunidade científica (representada, na classe, pelo resto das equipes, o corpo de conhecimentos já construídos, os textos, o professor como "perito"...).

Faz-se ver, em particular, que os resultados de uma só pessoa ou de uma só equipe não bastam para verificar ou falsear uma hipótese.

Contempla-se (e utiliza-se) o corpo de conhecimentos disponíveis como a consolidação do trabalho realizado pela comunidade científica e a expressão do consenso, nem sempre alcançado².

Fonte: Modificado de Cachapuz et al. (2005).

\footnotetext{
${ }^{2}$ Cachapuz et al. (2005) utilizam a expressão "cristalização do trabalho realizado pela comunidade científica e expressão do consenso alcançado". Considero que "cristalizado" remete a uma visão estática da produção do conhecimento científico, em constante transformação. Da mesma forma, é preciso destacar que a ideia de consenso em ciência nem sempre é possível.
} 
da construção e produção científica, que o professor tem de conhecer e não se pode alhear, deixando à margem das suas aulas. Caso contrário, a experiência científica escolar toma o sentido do fazer, sem saber por que e para quê. Estamos, neste caso, a considerar a ciência numa lógica que está fora da própria história do pensamento as ideias, desvalorizando o sentido da própria luta por ideias mais verdadeiras, isto é, mais explicativas para os fenômenos naturais. (PRAIA; CACHAPUZ; GIL-PÉREZ, 2002, p. 258)

Na mesma direção, Coquidé (2008) também relata, em pesquisa realizada na França, que a visão dos professores investigados acerca da prática experimental deixa subentendido que, para eles, é suficiente "fazer para compreender" e "ver para provar".

Muitos dos objetivos que se estabelecem para o trabalho experimental escolar e que os professores quase sempre enunciam referem-se, entre outros, ao seu forte sentido motivador (PRAIA; CACHAPUZ; GIL-PÉREZ, 2002), o que constitui o segundo mito que será analisado a seguir.

Mito 2: A realização de atividades práticas garante a motivação dos alunos.

De acordo com Galiazzi e Gonçalves (2004), alguns estudos sobre experimentação afirmam que os professores a consideram importante porque motiva intrinsecamente os alunos. Cabe, entretanto, problematizar essa asserção - assim como o fazem os referidos autores, visto que os mesmos estudos revelam que isso pouco ocorre durante as aulas experimentais.

Essa ideia presente no pensamento dos professores está associada a um conjunto de entendimentos empiristas de Ciência em que a motivação é resultado inerente da observação do aluno sobre o objeto de estudo. Isto é, os alunos se motivam justamente por "verem" algo que é diferente da sua vivência diária, ou seja, pelo "show" da ciência. (GALIAZZI; GONÇALVES, 2004, p. 328)

Praia, Cachapuz e Gil-Pérez (2002, p. 260) também chamam a atenção para “a tentação de uma excessiva motivação para experimentar e que o professor, bem intencionadamente, introduz na aula de laboratório", a qual pode desviar o foco da aprendizagem. Segundo eles:

A espectacularidade dos fenômenos, aliada à sua apresentação, nomeadamente, quer através de registros, vídeo, quer outros, ainda que sejam fatores positivos, podem não ajudar a potenciar a aprendizagem desejada. Pode mesmo invertê-la e torná-la sociologicamente perversa, ou seja, pode desvalorizar razões epistemológicas e didáticas que deviam ser orientadoras e determinantes da ação, em favor de razões de pedagogia geral, em particular motivacionais que fazem perder o sentido das primeiras. (PRAIA; CACHAPUZ; GIL-PÉREZ, 2002, p. 260) 
Mais uma vez, remanescem, nestas visões, concepções simplistas sobre a experimentação, derivadas de uma visão deformada sobre a natureza da ciência, que, também, está por detrás do terceiro mito analisado neste trabalho.

\section{Mito 3: É indispensável um laboratório de ciências para a realização de atividades práticas.}

Dos mitos apresentados aqui, provavelmente, este é o mais facilmente refutável, sobretudo levando-se em conta a realidade das escolas brasileiras, em que se observam tanto escolas com laboratórios ociosos - utilizados mais como depósito e almoxarifado, do que como local de ensino-aprendizado - quanto escolas que não possuem infraestrutura laboratorial mas que realizam atividades práticas em locais improvisados e com materiais de baixo custo e/ou emprestados. Nesta direção, destacam-se as ações colaborativas entre espaços não formais e formais, que vêm contribuindo tanto com o empréstimo de materiais e "kits", como na formação de professores (BASSOLI, 2013).

De acordo com Zompero e Laburu (2011), a perspectiva indutivista foi uma justificativa para o surgimento de práticas na educação científica que envolviam a utilização do laboratório, as quais receberam apoio do cientista e filósofo positivista, do século XIX, Herbert Spencer. Segundo esses autores, a utilização do laboratório, na concepção do filósofo, poderia promover a melhor compreensão dos fenômenos naturais, partindo do pressuposto de que a observação do mundo e as atividades de laboratório fornecem informações claras e precisas sobre a natureza, que não se encontram nos livros.

Assim, de acordo com uma perspectiva mais racionalista e atualizada sobre a ciência, Duschl (2004) apresenta algumas mudanças na utilização do laboratório didático e nas atividades investigativas no ensino, cujo enfoque se deslocou do ensino "do que" nós conhecemos, ou seja, do conhecimento produzido e acumulado, para uma educação científica que enfatiza o "como" nós conhecemos; de uma educação científica que salienta o ensino de conteúdos, para uma educação com ênfase na relação entre evidências e explicações; da demonstração de conceitos, para o ensino que promove o raciocínio "com" e "sobre" os conceitos; de uma visão que salienta a observação e a experimentação, para uma visão que enfatiza a construção de modelos e a observação guiada por uma teoria (DUSCHL, 2004).

\section{Considerações finais: por uma maior aproximação ao cotidiano escolar}

Para concluir, recorro a um último resquício academicista, ao evocar, novamente, a pesquisa de Andrade e Massabni (2011), e volto-me para o "chão de giz" que me rodeia, destoando do "ritmo" que impus a esse texto até então. De acordo com estes autores, embora as professoras de ciências investigadas em sua pesquisa valorizassem as atividades práticas, raramente as utilizavam, em função de diversas razões como: insegurança, falta de apoio e infraestrutura da escola, sentindo-se, portanto, angustiadas por não conseguirem desenvolvê-las.

É importante destacar que, além dos aspectos epistemológicos e didáticos enfatizados neste artigo, assim como os aspectos materiais citados em diversos trabalhos, há que se considerar, além das políticas públicas, sobretudo, os aspectos humanos - os quais são tão importantes 
quanto os primeiros, tendo em vista que, sem disciplina, respeito, cooperação e engajamento, por exemplo, qualquer aula - experimental ou não - tende ao fracasso.

A despeito da importância destes aspectos para o ensino-aprendizagem, raros trabalhos os abordam, de modo que, normalmente, a indisciplina e falta de motivação dos alunos são vistas como consequência de um ensino maçante e essencialmente expositivo, da falta de preparo ou, até mesmo, da falta de motivação dos próprios professores.

Coloco esta questão para uma reflexão sobre a complexidade do processo educacional, de modo a problematizar, não só as concepções distorcidas sobre a natureza da ciência, mas, também, as relações simplistas que, normalmente, são estabelecidas entre o ensino e a aprendizagem, culminando, ora na culpabilização dos professores, ora dos alunos, ora dos cursos de formação de professores, ora da direção das escolas. Desconsiderando-se a imbricada rede de relações que são estabelecidas entre os vários agentes do processo educacional (incluindo os alunos!), assim como os diferentes contextos em que estas relações se processam.

Nesse sentido, destaco a importância de se discutirem as atividades práticas em contextos reais, onde se conflitam as deficiências formativas dos professores e dos alunos com a falta de "infraestrutura", tanto das escolas, como dos professores, dos alunos e de suas famílias. Neste cenário, promover atividades práticas é um ato de heroísmo em que conseguir realizar atividades práticas investigativas, aproximando a sala de aula do contexto de produção do conhecimento científico, é superar, definitivamente, os inúmeros entraves que impedem a melhoria da qualidade da educação no Brasil.

Finalizo este trabalho, não desconstruindo toda a cadeia argumentativa desenvolvida até então, mas compartilhando de uma angústia ainda maior que a manifestada pelas professoras do estudo de Andrade e Massabni (2011): a angústia da busca da coerência entre a teoria - apreendida em um processo permanente de estudo e pesquisa - e a prática profissional, permeada por todo tipo de dificuldades intrínsecas ao trabalho de e com seres humanos.

\section{Referências}

ANDRADE, M. L. F.; MASSABNI, V. G. O desenvolvimento de atividades práticas na escola: um desafio para os professores de ciências. Ciência \& Educação, Bauru, v. 17, n. 4, p. 835-854, 2011. Disponível em: <http://dx.doi.org/10.1590/S1516-73132011000400005>. Acesso em: 06 ago. 2012.

BASSOLI, F. O processo de apropriação da bioexposição "A célula ao alcance da mão" em um centro de ciências: desafios da mediação. Ensaio, Belo Horizonte, v. 15, n. 1, p. 155-174, 2013. Disponível em: <http://www.portal.fae.ufmg.br/seer/index.php/ensaio/article/view/770/1160>. Acesso em: 01 jul. 2014.

BEVILACQUA, G. D.; COUTINHO-SILVA, R. O ensino de ciências na $5^{\mathrm{a}}$ série através da experimentação. Ciências \& Cognição, Rio de Janeiro, v. 10, p. 84-92, 2007. Disponível em: $<$ http://www.cienciasecognicao.org/revista/index.php/cec/article/view/615>. Acesso em: 06 ago. 2012. 
Bassoli, F.

BRASIL. Ministério da Cultura e do Desporto. Secretaria de Educação Fundamental. Parâmetros curriculares nacionais: ciências naturais $5^{\text {a }}$ a $8^{\text {a }}$ séries. Brasília, 1998.

CACHAPUZ, A. et al. A necessária renovação do ensino de ciências. São Paulo: Cortez, 2005.

CAMPOS, M. C. C.; NIGRO, R. G. Didática de ciências: o ensino-aprendizagem como investigação. São Paulo: FTD, 1999.

CHALMERS, A. F. O que é ciência afinal? 2. ed. São Paulo: Brasiliense, 1993.

CHASSOT, A. Ensino de ciências no começo da segunda metade do século da tecnologia. In:

LOPES, A. C.; MACEDO, E. Currículo de ciências em debate. Campinas: Papirus, 2004. p. 13-44.

COQUIDÉ, M. Um olhar sobre a experimentação na escola primária francesa. Ensaio: pesquisa em educação em ciências, Belo Horizonte, v. 10, n. 1, p. 1-18, 2008. Disponível em: < http://redalyc. uaemex.mx/redalyc/pdf/1295/129516851010.pdf>. Acesso em: 06 ago. 2012.

DEBOER, G. E. Historical perspectives on inquiry teaching in schools. In: FLICK, L. B.;

LEDERMAN, N. G. Scientific inquiry and nature of science: implications for teaching, learning, and teacher education. Berlin: Springer, 2006. p. 17-36.

DUSCHL, R. Science education in three-part harmony: balancing conceptual, epistemic, and social learning goals. Review of Research in Education, Thousand Oaks , v. 32, n. 1, p. 268-291, 2008. Disponível em: <http://rre.sagepub.com/content/32/1/268.short>. Acesso em: 01 ago. 2012.

DUSCHL, R. A. The HS lab experience: reconsidering the role of evidence, explanation and the language of science - paper prepared for the Committee on High School Science Laboratories: role and vision. Washington: National Research Council, 2004.

Disponível em: <http://www4.nationalacademies.org/xpedio/idcplg?IdcService=GET_ FILE\&dDocName=DBASSE_073329\&RevisionSelectionMethod=Latest $>$. Acesso em: 06 ago. 2012.

GALIAZZI, M. C.; GONÇALVES, F. P. A natureza pedagógica da experimentação: uma pesquisa na licenciatura em química. Química Nova, São Paulo, v. 27, n. 2, p. 326-331, 2004. Disponível em: <http://www.scielo.br/pdf/qn/v27n2/19283.pdf>. Acesso em: 06 ago. 2012.

GOMES, A. D. T.; BORGES, A. T.; JUSTI, R. Processos e conhecimentos envolvidos na realização de atividades práticas: revisão da literatura e implicações para a pesquisa. Investigações em Ensino de Ciências, Porto Alegre, v. 13, n. 2, p. 187-207, 2008. Disponível em: <http://www.if.ufrgs.br/ ienci/artigos/Artigo_ID194/v13_n2_a2008.pdf>. Acesso em: 06 ago. 2012.

KRASILCHIK, M. Reformas e realidade: o caso do ensino de ciências. São Paulo em Perspectiva, São Paulo, v. 14, n. 1, p. 85-93, 2000.

KRASILCHIK, M. P. Prática de ensino de biologia. 4. ed. São Paulo: Edusp, 2008.

MARANDINO, M. (Org.). Educação em museus: a mediação em foco. São Paulo: Geenf; FEUSP, 2008. Disponível em: <http://www.geenf.fe.usp.br/publica.php>. Acesso em: 20 jul. 2012.

MUNFORD, D.; LIMA, M. E. C. C. Ensinar ciências por investigação: em que estamos de acordo? Ensaio: pesquisa em educação em ciências, Belo Horizonte, v. 9, n. 1, p. 72-89, 2007. Disponível em: < http://www.portal.fae.ufmg.br/seer/index.php/ensaio/article/view/122/172>. Acesso em: 06 ago. 2012. 
PAVÃO, A. C.; LEITÃO, A. Hands-on? Minds-on? Hearts-on? Social-on? Explainers-on! In: MASSARANI, L.; MERZAGORA, M.; RODARI, P. (Org.). Diálogos \& ciência: mediação em museus e centros de ciência. Rio de Janeiro: Museu da Vida, 2007. p. 39-46. Disponível em: <http:// www.museudavida.fiocruz.br/media/Mediacao_final.pdf>. Acesso em: 09 jan. 2012.

PRAIA, J.; CACHAPUZ, A.; GIL-PÉREZ, D. A hipótese e a experiência científica em educação em ciência: contributos para uma reorientação epistemológica. Ciência \& Educação, Bauru, v. 8, n. 2, p. 253-262, 2002. Disponível em: <http://dx.doi.org/10.1590/S1516-73132002000200009>. Acesso em: 03 ago. 2012.

RAMOS, L. B. C.; ROSA, P. R. S. O ensino de ciências: fatores intrínsecos e extrínsecos que limitam a realização de atividades experimentais pelo professor dos anos iniciais do ensino fundamental. Investigações em Ensino de Ciências, Porto Alegre, v. 13, n. 3, p. 299-331, 2008.

TRÓPIA, G. B. A. Percursos históricos de ensinar ciências através de atividades investigativas.

Ensaio: pesquisa em educação em ciências, Belo Horizonte, v. 13, n. 1, p. 121-138, 2011. Disponível em: <http://www.portal.fae.ufmg.br/seer/index.php/ensaio/article/viewArticle/245>. Acesso em: 31 jul. 2012.

TRÓPIA, G. B. A. Relações dos alunos com o aprender no ensino de biologia por atividades investigativas. 2009. 202 f. Dissertação (Mestrado em Educação Científica e Tecnológica) Universidade Federal de Santa Catarina, Florianópolis, 2009. Disponível em: <https://repositorio. ufsc.br/bitstream/handle/123456789/93177/266452.pdf?sequence=1>. Acesso em: 31 jul. 2012.

ZANON, D. A. V.; FREITAS, D. A aula de ciências nas séries iniciais do ensino fundamental: ações que favorecem sua aprendizagem. Ciências \& Cognição, Rio de janeiro, v. 10, p. 93-103, 2007.

ZOMPERO, A. F.; LABURU, C. E. Atividades investigativas no ensino de ciências: aspectos históricos e diferentes abordagens. Ensaio: pesquisa em educação em ciências, Belo Horizonte, v. 13, n. 3, p. 67-80, 2011. Disponível em: <http://www.portal.fae.ufmg.br/seer/index.php/ensaio/article/view/309/715>. Acesso em: 01 ago. 2012. 